\title{
Research on Power Quality Evaluation of Wind Farm Based on Fuzzy Neural Network
}

\author{
Ji-cheng Liu ${ }^{1}$, Jing $\mathrm{Yu}^{1}{ }^{1,}, \mathrm{Fu}-$ lian $\mathrm{Shi}^{1}$ and Na-na Cai ${ }^{2}$ \\ ${ }^{1}$ School of Economics and Management, North China Electric Power University, \\ Beijing, 102206, China \\ ${ }^{2}$ Beijing Productivity Center, Beijing, 100088, China \\ "yj_ncepu@163.com
}

\begin{abstract}
Power quality is the key factor that influences the stability and security of grid system with the wind power integration. Strengthening the evaluation research of power quality of wind farm has significant influence. This paper constructs the fuzzy neural network model to evaluate the power qualities of different observation points of wind farm, and uses certain power quality classifications to verify the security and stability of wind power in grid-connection. Numerical example analysis will verify that the model in this paper is reasonable and subjective in power quality classification determination, and corresponding power evaluation result in the same classification is characterized by high identification degree and high resolution, which has advisory value for decision making.
\end{abstract}

Keywords: wind farm, power quality, fuzzy neural network, evaluation

\section{Introduction}

Over consumption and continuous pollution of traditional fossil energy lead to the development of renewable energy. Among which, wind power, characterized by infinite resource, convenient obtaining, little environment pollution, has attracted worldwide attention. Chinese wind resource and power market are contrarily distributed, as a result, power of wind farm cannot be consumed locally or connected with the grid easily. Furthermore, the volatility and intermittence of wind power have significant influence on power quality and peak regulation ability of public grid-connection point, and the grid stability might be impacted as well. And the biggest problem of wind power gridconnection is the power quality problems, such as voltage deviation, voltage fluctuation and harmonic voltage. Therefore, research on power quality evaluation of wind power grid-connection has reference value for the power quality classification evaluation of wind farm grid-integration points, other power supply points and the power pricing [1-3].

Current comprehensive evaluation methods on power quality of wind farm include grey correlation, cloud matter model, cloud barycenter theory and analytic hierarchy process. To reduce the observation cost, Ali Sardar and Wu Kui (2015) adopted a learnfrom-data approach to obtain a device latent feature model, which captured the device behavior as a PQ transition function [4]. Based on the situation that power quality evaluation is impacted by human factors, Fu Xueqianand Chen Haoyong (2015) put forward an evaluation method with weighted rank sum ratio [5]. Under the background of big data analysis, Zhang Huaying, Zhu Zhengguo et al (2015) proposed a transient evaluation method which extended data source to observation data of grid operation and consumer data [6]. Wang Lei and Wang Qiusha (2015) adopted an evaluation model based on cloud barycenter to solve the problem of uncertainty of observation data for subjective and reasonable result [7]. While indexes of power are complicated and nonlinear, Zhao Xian, Zhou Lixing et al (2014) put forward three standard degrees updated analytic hierarchy process to evaluate the power quality [8]. In recent years, 
neural network can approximate the nonlinear relationship between the input and output by arbitrary precision, so it is widely used in relevant evaluation study .Song Lingli et al(2015) proposed an integrate evaluation method for operation efficiency of power, which is based on fuzzy neural network[9].For the fuzziness of classification of water quality standards, Zhao Xu, Chen Lili (2015) introduced the theory of fuzzy neural network, and established the evaluation model of water environment quality [10].Since power in the same classification is characterized by low identification degree and low resolution, this paper puts forward an evaluation method with fuzzy neural network.

\section{Evaluation Indexes of Power Quality of Wind Farm}

Power quality is decided by the distance between real situation of grid and the ideal system. As to the sustainable three-phase AC voltage, the waveform of its current and voltage should be sinusoidal and distortionless, and its frequency amplitude should be in the allowed range. Power of wind farm connects the grid in points of common coupling (PCC), and during this process, 6 kinds of major power quality pollutions might happen, including frequency offset, voltage deviation, voltage fluctuation, voltage flicker, harmonic voltage and three-phase unbalance. These problems will influence the security operation of wind farm and the grid system and the equipment. Especially that harmonic pollution will have impact on power grid, electronic equipment and communication line [11].

In this basis, the evaluation index system is constructed as following Figure 1.

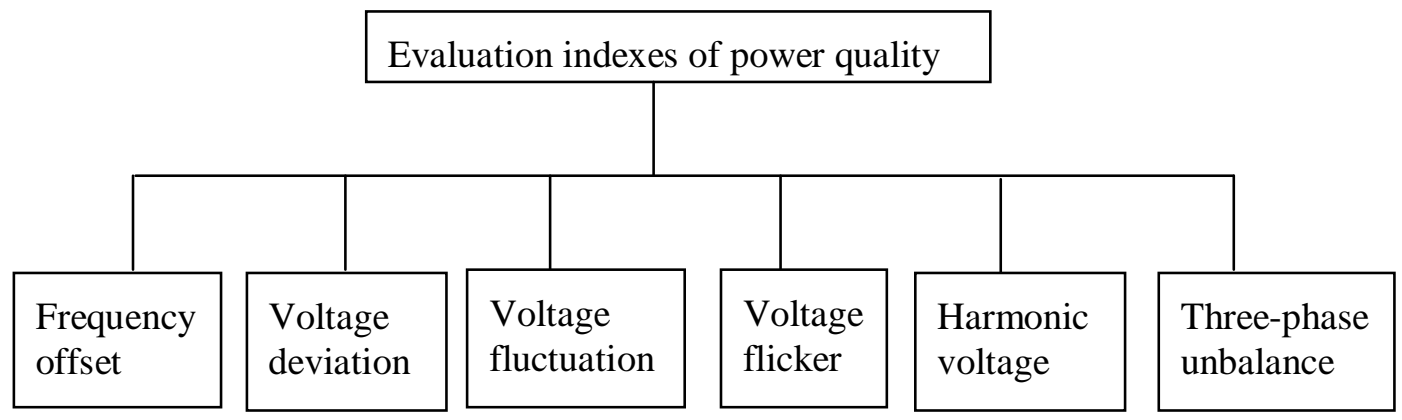

Figure 1. Evaluation Indexes of Power Quality of Wind Farm

\section{Fuzzy Neural Network Model of Power Quality Evaluation of Wind Farm}

Fuzzy System (FS) combines with Neural Network (NN) to create the Fuzzy Neural Network (FNN). FNN can avoid the disadvantages of fuzzy logic in learning of FS and fuzzy data processing of $\mathrm{NN}$, and it has language calculation ability, distributed processing ability, logical thinking ability and nonlinear dynamics ability.

\subsection{Fuzzy Neural Network Model Construction}

(1) Standardization of sample matrix and standard index matrix

Suppose $n$ indexes of the sample set of power quality need identification and each of them has $m$ factors (in this paper, $m=6$ ), namely the observation index matrix is $X_{m \times n}=\left(x_{i j}\right)_{m \times n}$ [12]. Let $Y_{m \times c}=\left(y_{i h}\right)_{m \times c}$ be the standard index matrix, and $c_{\text {means the }}$ standard classification of factors. If the evaluation interval of power quality is of numerical interval type, take its standard value of classification as the evaluation degree. 
$c(c=5)$ is also the standard classification number; the standard value of $\mathrm{h}$-th standard classification index is $y_{i h}$, and $h$ is the classification of standard identification matrix, $h=1,2, \ldots, c$. Since power quality is fuzzy and sustainably changed, this paper uses relative membership degree to describe its fuzziness [13-14]: if the relative membership of "Good" power quality belongs to the first standard value classification of standard matrix, let its membership degree be 1; if the relative membership of "Good" power quality belongs to c-th standard value classification of standard matrix, let its membership degree be 0 ; if the relative membership of "Good" power quality belongs to value among the range of $(1, c)$, its membership degree can be obtained with following Equation (1):

$$
s_{i h}=1-\left(y_{i h}-y_{i 1}\right) /\left(y_{i c}-y_{i 1}\right)
$$

Transform matrixes $X_{m \times n}$ and $Y_{m \times c}$ into corresponding index relative membership degree matrix $R_{m \times n}=\left(r_{i j}\right)_{m \times n}$, the standard index relative membership degree matrix is $S_{m \times c}=\left(s_{i h}\right)_{m \times c}$, relative membership degree $u_{h i}$ means the classification of sample ${ }^{j}$ is $h(h=1,2, \ldots, c)$, and the relative membership degree matrix of degrees is $U_{c \times n}=\left(u_{h j}\right)_{c \times n}$, whose constraint condition is shown in following Equation (2):

$$
\sum_{h=1}^{c} u_{h j}-1=0,0<u_{h j}<1, \forall h, \forall j
$$

(2) Fuzzy neural network model construction

To determine the classification of power quality, the membership degree matrix of trained fuzzy neural network is obtained and shown in Equation (2), and this comprehensive evaluation model chooses a three-layer BP network, including the input layer, the hidden layer and the output layer. Since there are 6 indexes and 5 classifications in this paper, the numbers of input neuron and output neuron is respectively 6 and 5 . Calculate the number of hidden layer neuron with Equation (3) [15]:

Number of hidden layer neuron $=$

$$
\text { (input layer neuron number } \times \text { output layer neuron number) }{ }^{1 / 2}
$$

According to calculation, the number of hidden layer neuron is 5 and the fuzzy neural network structure is shown in Figure 2. 


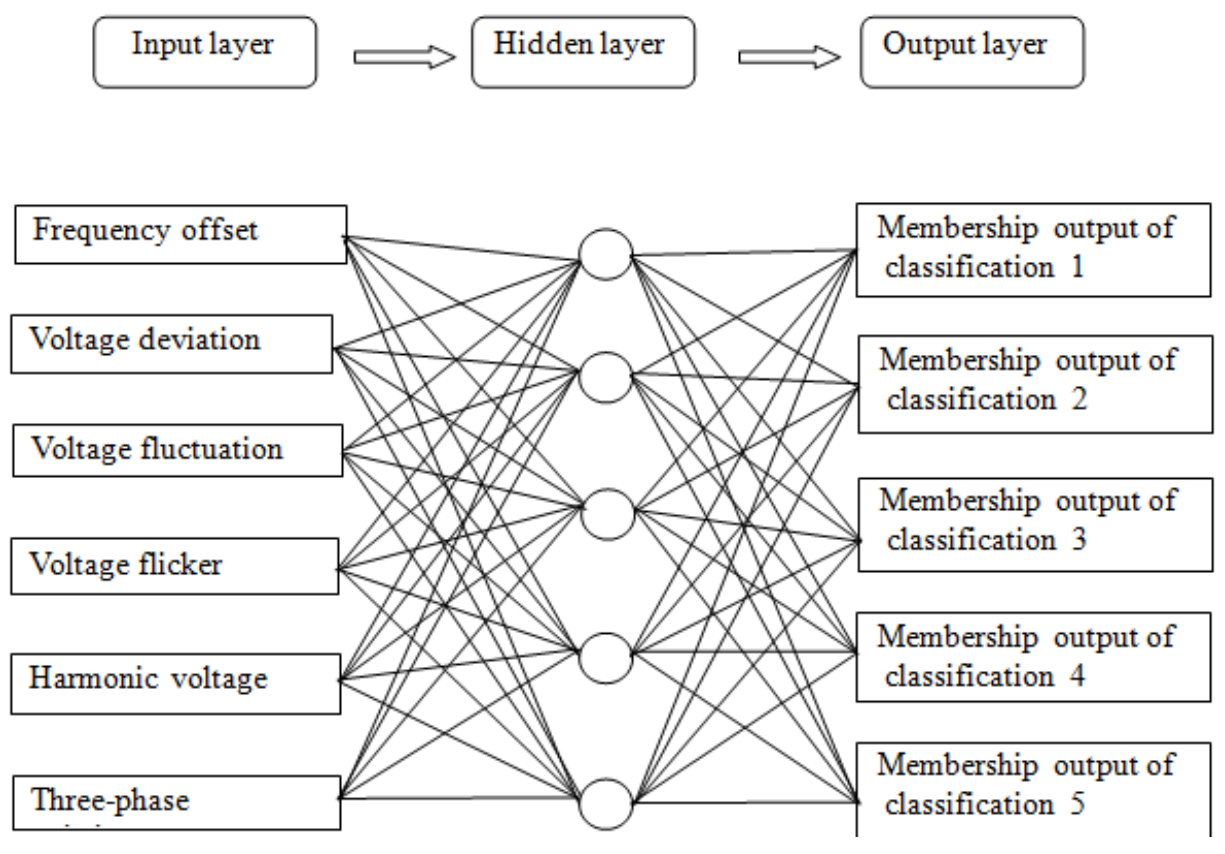

Figure 2. Fuzzy Neural Network Structure

During network learning process, the input of forward transportation is the basic information of training sample and the reverse transportation contains the error and modification information. Usually, the encouragement function is the sustainable derivable bounded sigmoid function, the non-derivable step function, or the radial basis function [16]. Considering the wild application of sigmoid function, this paper adopts sigmoid function as the encouragement function.

(3) Creating training sample

It can be seen from the standard of power quality, that various indexes have their upper and lower limits, and if every component of sample data is in the allowed range of certain classification of power quality standard, we can determine the classification of this sample. Therefore, using finite interpolation method (or random sampling method) to process the power quality can obtain enough training sample to satisfy data requirement of the model [17]. We adopt this method to create 3,000 samples as the testing and detection samples, separately select 500 samples from these two sample groups, and the rest 2,000 samples are chosen as the training samples. Standard membership degree training samples and corresponding membership degree values are shown in Table 1.

(4) Flow figure of fuzzy neural network model

Flow figure of calculation process based on above methods is shown in following Figure 3. 


\section{Table 1. Standard Classification Index Values for Training and Corresponding Membership Degree Values}

\begin{tabular}{|l|lllllllll|}
\hline \multirow{2}{*}{ Classifications } & \multicolumn{3}{|c}{ Training samples of $\mathrm{S}_{\mathrm{m} \times \mathrm{c}}$} & \multicolumn{5}{c|}{$\begin{array}{c}\text { Corresponding membership } \\
\text { degree values of samples }\end{array}$} \\
\cline { 2 - 9 } & 1 & 2 & $\ldots$ & $\mathrm{m}$ & 1 & 2 & 3 & $\ldots$ & $\mathrm{n}$ \\
\hline Classification 1 & $\mathrm{~s}_{11}$ & $\mathrm{~s}_{21}$ & $\ldots$ & $\mathrm{s}_{\mathrm{m} 1}$ & 1 & 0 & 0 & 0 & \\
$1 / 2$ Interpolation & $\left(\mathrm{s}_{11+} \mathrm{s}_{12}\right) / 2$ & $\left(\mathrm{~s}_{21+} \mathrm{s}_{22}\right) / 2$ & $\ldots$ & $\left(\mathrm{s}_{\mathrm{m} 1+} \mathrm{s}_{\mathrm{m} 2}\right) / 2$ & 0.5 & 0.5 & 0 & 0 & 0 \\
$1 / 4$ Interpolation & $\left(3 \mathrm{~s}_{11+} \mathrm{s}_{12}\right) / 4$ & $\left(3 \mathrm{~s}_{21+} \mathrm{s}_{22}\right) / 4$ & $\ldots$ & $\left(3 \mathrm{~s}_{\mathrm{m} 1+} \mathrm{s}_{\mathrm{m} 2}\right) / 4$ & 0.75 & 0.25 & 0 & 0 & 0 \\
$\ldots$ & $\ldots$ & $\ldots$ & $\ldots$ & $\ldots$ & $\ldots$ & $\ldots$ & $\ldots$ & $\ldots$ & $\ldots$ \\
Classification 2 & $\mathrm{~s}_{12}$ & $\mathrm{~s}_{22}$ & $\ldots$ & $\mathrm{s}_{\mathrm{m} 2}$ & 0 & 1 & 0 & 0 & 0 \\
$\ldots$ & $\ldots$ & $\ldots$ & $\ldots$ & $\ldots$ & $\ldots$ & $\ldots$ & $\ldots$ & $\ldots$ & $\ldots$ \\
Classification c & $\mathrm{s}_{1 \mathrm{c}}$ & $\mathrm{s}_{\mathrm{c} 2}$ & $\ldots$ & $\mathrm{s}_{\mathrm{mc}}$ & 0 & 0 & 0 & 0 & 1 \\
\hline
\end{tabular}

Data source: "Evaluate power quality with fuzzy neural network model"

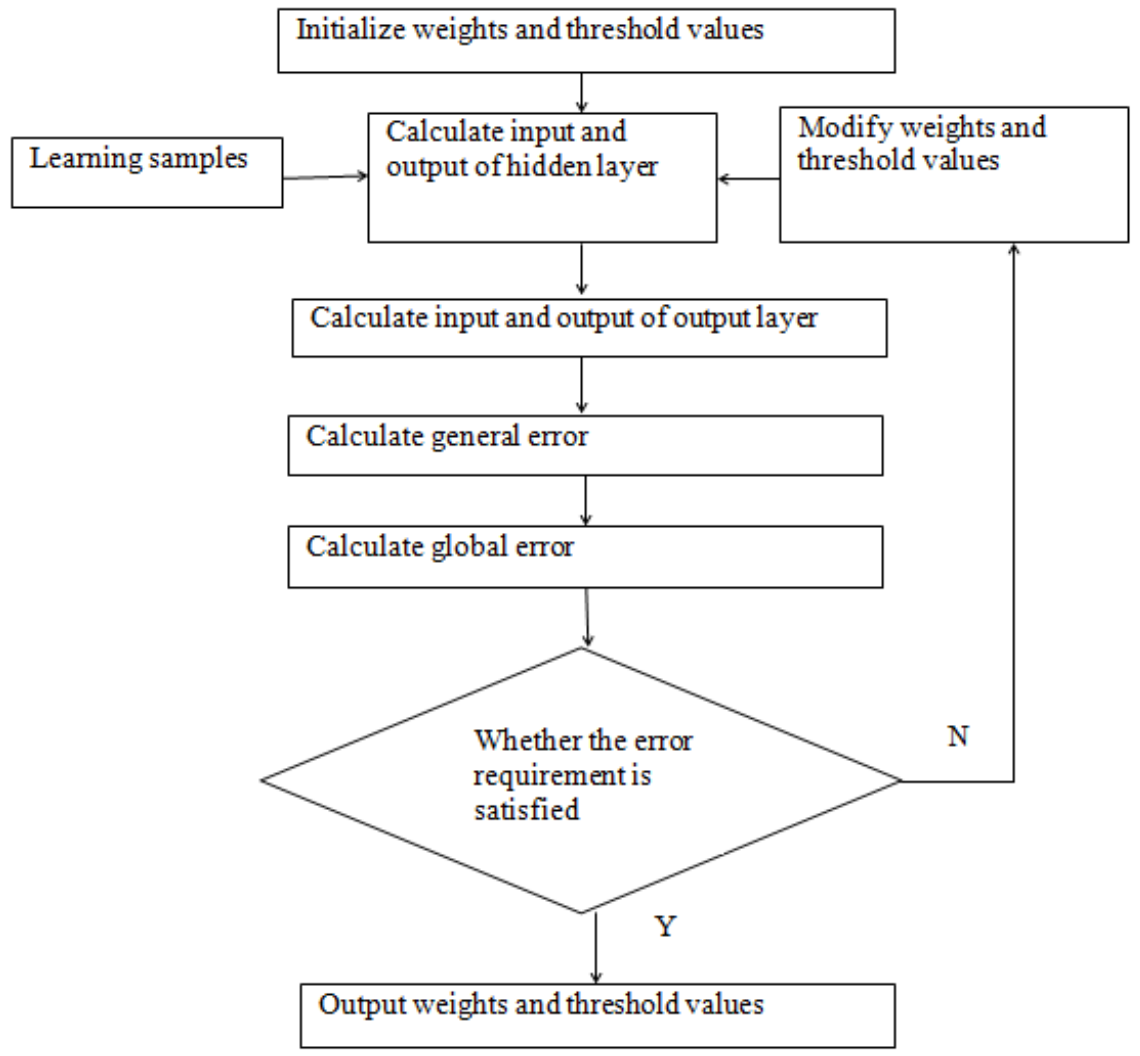

Figure 3 Flow Figure of Fuzzy Neural Network Model

\subsection{Determining Classification of Power Quality}

Considering maximum membership degree law, classification condition does not exist in undefined concept, so we use classification eigenvalue to determine classification of power quality with Equation (4):

$$
T_{1}=[1,2,3, \ldots, c] \times U_{c \times n}=\left[t_{1}, t_{2}, t_{3}, \ldots, t_{n}\right]
$$

In Equation (4), $c-1<t_{j} \leq c$, if $t_{j}=c$, then power quality of sample $j$ belongs to classification ${ }^{c}$ [18]. 
Based on the fuzzy concept, normalizing the classification eigenvalue matrix in Equation (4) for further fuzzy process to obtain Equation (5):

$$
T_{2}=[1,2,3, \ldots, c] \times\left[\frac{T_{1}}{\sum_{j=1}^{c} t_{j}}\right]^{T}
$$

Then we can determine the classification of power quality of wind farm.

\section{Numerical Example Analysis}

\subsection{Practical Numerical Example}

Select 5 main transformer substation bus nodes of certain large wind farm for wind quality observation and obtain 5 wind quality index data sets [19]. These 5 bus nodes include: $10 \mathrm{KV}$ bus nodes of Jinniu transformer substation, denoted by A; $110 \mathrm{KV}$ bus nodes of Waipu transformer substation, denoted by B; 10KV bus nodes of Niu Touling transformer substation, denoted by $\mathrm{C} ; 35 \mathrm{KV}$ bus nodes of $\mathrm{Zu}$ Zaiao transformer substation, denoted by $\mathrm{D} ; 10 \mathrm{KV}$ bus nodes of Da Lankou transformer substation, denoted by E. And corresponding power quality observation data is shown in Table 2 .

Table 2. Initial Data Set of Wind Quality in Different Measuring Points

\begin{tabular}{|c|c|c|c|c|c|c|}
\hline $\begin{array}{l}\text { Observation } \\
\text { points }\end{array}$ & $\begin{array}{l}\text { Frequency } \\
\text { offset } / \mathrm{Hz} \\
\text { deviation } \\
/ \%\end{array}$ & $\begin{array}{l}\text { Voltage } \\
\text { fluctuation } \\
/ \%\end{array}$ & $\begin{array}{l}\text { Voltage } \\
\text { flicker } \\
/ \%\end{array}$ & $\begin{array}{c}\text { Harmonic } \\
\text { voltage } / \%\end{array}$ & $\begin{array}{c}\text { Three-phase } \\
\text { unbalance } \\
/ \%\end{array}$ \\
\hline $\mathrm{A}$ & 0.09 & 2.53 & 0.96 & 0.22 & 1.12 & 0.88 \\
\hline $\mathrm{B}$ & 0.04 & 1.66 & 1.05 & 0.34 & 1.26 & 1.07 \\
\hline $\mathrm{C}$ & 0.19 & 3.85 & 1.41 & 0.47 & 1.18 & 0.83 \\
\hline $\mathrm{D}$ & 0.11 & 2.01 & 0.85 & 0.38 & 0.82 & 0.58 \\
\hline $\mathrm{E}$ & 0.07 & 3.18 & 1.27 & 0.53 & 1.35 & 1.23 \\
\hline
\end{tabular}

Data source: "Wind farm power quality analysis and evaluation"

\subsection{Wind Farm Power Quality Evaluation with Fuzzy Neural Network Model}

Select 5 observation points with 6 evaluation indexes to obtain groups of data as the samples. Input relative membership degrees of sample data into the trained fuzzy neural network, and we can obtain relative membership degree matrix $U_{5 \times 5}$ of observation data of power quality compared with standard classification.

$$
U_{5 \times 5}=\left[\begin{array}{ccccc}
0.424 & 0.0005 & 0 & 0 & 0.3122 \\
0.5712 & 0.4326 & 0 & 0 & 0.6316 \\
0.0048 & 0.5669 & 0 & 0.2445 & 0.0562 \\
0 & 0 & 0.3321 & 0.7213 & 0 \\
0 & 0 & 0.6679 & 0.0342 & 0
\end{array}\right]
$$

Using Equation (4) and (5) to obtain matrix $T_{1}$ and $T_{2}$ :

$$
T_{1}=[1,2,3,4,5] \times U_{5 \times 5}=[1.5898,2.5644,4.6679,1.744,2.6317]
$$




$$
T_{2}=[1,2,3,4,5] \times\left[\frac{T_{1}}{\sum_{j=1}^{5} t_{j}}\right]^{T}=[1,2,3,4,5] \times[0.12046,0.19431,0.35369,0.13214,0.1994]^{T}
$$

According to determining method of power quality, we can obtain the power quality classifications of 5 evaluation points, which are shown in Table 3.

Table 3. Evaluation Result of Model

\begin{tabular}{|clllll|}
\hline Evaluation points & 1 & 2 & 3 & 4 & 5 \\
\hline Evaluation result & 1 & 2 & 4 & 1 & 2 \\
\hline
\end{tabular}

We used fuzzy neural network model to evaluate power quality of observation points, and the comprehensive evaluation result of this wind farm belongs to classification 3 , a fine power quality situation.

\section{Conclusions}

Applying fuzzy neural network model into power quality evaluation can determine the quality classification of wind farm and the difference of certain classification, which reflects that model in this paper has strong scheduling and classifying abilities. By using fuzzy neural network model to evaluate power quality of different observation points of wind farm, we can determine the security of wind power integration. Evaluation result with model in this paper is reasonable and subjective, and power evaluation in the same degree is characterized by high identification degree and high resolution, which has advisory value for decision making. However, research in this paper needs improvement in adding to more evaluation indexes, meanwhile, wind farm with more complicated constraints cannot obtain correct evaluation results with model in this paper. So far, wind power integration has many technical problems which need to be solved, and it requires more research.

\section{References}

[1] M. Su, "Power pricing method research of multiple quality classification based on risk management", North China Electric Power University (Baoding), Hebei, (2006).

[2] N. N. Cai, "Power quality evaluation model research of wind farm with wind power grid-connection consideration", North China Electric Power University, (2015).

[3] J. C. Liu, S. H. Wang, D. X. Wu, "Risk Management Model of a Micro-Grid Wind Farm", Human and Ecological Risk Assessment, issue, 19, (2013), 1404-1417.

[4] A. Sardar, W. Kui, W. Kyle, "A Machine Learning Approach to Meter Placement for Power Quality Estimation in Smart Grid”, IEEE Transactions on Smart Grid, (2015), pp. 1-10.

[5] X. Q. Fu, H. Y. Chen, "Power quality comprehensive evaluation based on weighted rank sum ratio", Electric Power Automation Equipment, issue. 1, (2015), pp. 128-132.

[6] H. Y. Zhang, Z. G. Zhu, J. L. Yao, T. Gao, J. W. Cao, X. Han, M. Wang, "Transient power quality comprehensive evaluation based on big data analysis", Southern Power System Technology, issue. 6, (2015), pp. 80-86.

[7] L. Wang, Q. S. Wang, "Power quality comprehensive evaluation with cloud barycenter evaluation", Northeast Electric Power Technology, issue. 4, (2015), pp. 10-13.

[8] X. Zhao, L. X. Zhou, W. Deng, "Application of modified AHP in power quality comprehensive evaluation of distributed power system", Electric Power, issue. 12, (2014), pp.72-78.

[9] L. L. Song, L. G. Jia, B. W. Zhou, "Research on Operational Efficiency Assessment of Power Grid Based on Fuzzy Neural Network”, vol. 34, issue. 3, (2015), pp. 30-32. 
[10] X. Zhao, L. L. Chen, "Application of Fuzzy Neural in Water Environmental Quality Assessment”, Computer Knowledge and Technology, vol. 10, issue. 20, (2014), pp. 4813-4814.

[11] M. H. Jiang, X. J. Wang, J. Lou, J. H. He, "Influence study and solution analysis of electric railway harmonic on power calculation", Electrotechnical Application, issue. 20, (2013), pp. 68-71.

[12] B. H. Chowdhury, "Power quality", IEEE Potentials, vol. 20, issue. 2, (2001), pp. 5-11.

[13] B. Yue, H. K. Xie, "Evaluating the aging condition of main insulation in large generator based BP artificial neural network with fuzzy output", Zhongguo Dianji Gongcheng Xuebao, vol. 25, issue 2, (2005), pp. 76-81.

[14] Y. C. Liang, Y. M. Li, "Application of modified combinatorial radial basis function neural network in fault diagnosis of power transformer", High Voltage Engineering, vol. 31, issue 9, (2005), pp. 31-33.

[15] S. Krovvidy, W. G. Wee. "A knowledge based neural network approach for wastewater treatment system", IEEE INNS International Joint Conference on Neural Networks, San Diego, California, USA, (1990).

[16] M. Liu, T. F. Quan, S. H. Luan, "An attribute recognition system based on rough set theory fuzzy neural network and fuzzy expert system", Intelligent Control and Automation. Hangzhou, China, (2004).

[17] N. Amjady, "Day ahead price forecasting of electricity markets by a new fuzzy neural network", IEEE Transactions on Power Systems, vol. 21, issue. 2, (2006), 887-896.

[18] S Y. Chen, "Fuzzy set analysis theory and practice of engineering hydrology water resource system", Dalian University of Technology Press, Dalian, (1998).

[19] W. J. Hu, Z. G. Wu, Y. Zhang, Q. Zhong, "Wind farm power quality analysis and evaluation", Proceedings of the Chinese Society of Universities for Electric Power System and its Automation, vol. 21, issue. 4, (2009), pp. 82-87.

\section{Authors}
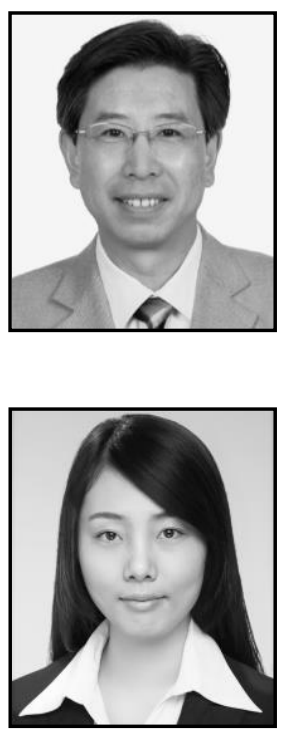

Ji-cheng Liu, (1963.9-) He is a professor in North China Electric Power University. He has doctorate and he is a doctoral supervisor of School of Economics and Management. His research interest is mainly in the area of power operation and information management, energy Internet theory and applications, etc. He has published several research papers in scholarly journals in the above research areas and has participated in several books.

Jing Yu, (1993.9-) She is pursuing her master's degree of Management Science and Engineering. Her main research directions are information management and decision support, energy Internet theory and applications. 